for delayed alteration in platelet aggregation and thromboelastography. This may result from the body's adjustment to large amounts of exogenous progestogen. It is also important to determine whether these less pronounced changes are reflected in significantly diminished risk of clinical thrombosis. This will have to be demonstrated by clinical study, assuming that the drug again becomes generally available.

The absence of any rise in clotting factors and the fact that raised clotting factors from combined preparations returned to normal and remained normal over the two-year period of study are encouraging features of progestogen-only contraception with chlormadinone acetate.

The work was performed while in receipt of a grant for thrombosis research from the Manchester Regional Hospital Board and from Syntex Pharmaceuticals Limited, who also supplied the chlormadinone acetate (Normenon).

\section{References}

Poller, L., Tabiowo, Anne, and Thomson, Jean M. (1968). British Medical

Journal, 3, 218.
Poller, L., Priest, Celia M., and Thomson, Jean M. (1969a). British Medical Fournal, 4, 273.

Poller, L., Thomson, Jean M., Tabiowo, Anne, and Priest, Celia M. (1969b). British Medical Fournal, 1, 554.

Poller, L., Priest, Celia M., and Thomson, Jean M. (1971). Journal of Physiology. To be published.

Ratnoff, O. D., and Menzie, C. (1951). Fournal of Laboratory and Clinical Medicine, 37, 316 .

Thomson, Jean M., and Poller, L. (1965). British Medical fournal, 2, 270.

\title{
Effect of Aspirin on Renal Clearance of ${ }^{125}$ I-Diatrizoate
}

\author{
LINDA BEELEY, M. J. KENDALL
}

British Medical fournal, 1971, 1, 707-708

\section{Summary}

Glomerular filtration rate was measured from the plasma disappearance curve after a single injection of sodium ${ }^{125} I$-diatrizoate. A therapeutic dose of aspirin in 13 subjects produced a mean fall in glomerular filtration rate of $10.5 \%$.

\section{Introduction}

Prolonged consumption of analgesic drugs is known to impair renal function (Nanra and Kincaid-Smith, 1970) but the acute effects of these drugs are unknown. Conventional methods for assessing glomerular filtration are either tedious to perform or too inaccurate to detect short-lived changes in renal function. Recent papers (Chantler, Garnett, Parsons, and Veall, 1969) have suggested that a single-injection technique by which renal clearance is calculated from the plasma disappearance of a radioactive substance correlates well with inulin clearance and is highly reproducible. We have therefore used the clearance of sodium ${ }^{125}$ I-diatrizoate (Hypaque) to study the acute effects of aspirin on glomerular filtration rate.

\section{Patients and Methods}

Fifteen medical inpatients were studied. All were informed of the nature and purpose of the studies and gave their consent. None had any impairment of renal function and all patients were in a steady state. All studies were performed at the same time of day and under the same conditions.

For the measurement of clearance a dose of radioactive Hypaque of approximately $0.4 \mu \mathrm{Ci} / \mathrm{kg}$ body weight was prepared in a 1-ml syringe and calculated accurately by weighing on a Mettler balance. About one-fifth of the dose was similarly weighed, diluted in a litre of water, and used as

Queen Elizabeth Hospital, Birmingham 15

LINDA BEELEY, M.A., M.R.C.P., Registrar, Department of Medicine M. J. KENDALL, M.R.C.P., Research Fellow a standard. The dose was diluted in $5 \mathrm{ml}$ of saline and given intravenously. Blood samples were taken at intervals and centrifuged, and the plasma was assayed for radioactivity, together with the standard, in a well-type scintillation counter. The results were used to plot the plasma disappearance curve of the injected Hypaque on a semilogarithmic scale (see Chart). Like other investigators (Denneberg, 1965), we found that after the intravenous administration of a single dose of labelled Hypaque the plasma activity falls off rapidly at first, but after one and a half to two hours the graph of plasma activity against time approximates closely to a single exponential curve. Three blood samples were therefore takenat two, three, and four hours after the injection of Hypaque.

For the calculation of plasma clearance the final part of the curve was extrapolated back to zero time to obtain the effective initial activity of the plasma (a). The theoretical volume of distribution $(\mathrm{V})$ is then given by:

$$
\mathrm{V}=\frac{\text { Dose }}{\mathrm{a}}
$$

The actual dose injected was obtained from:

$$
\text { Dose }=\frac{\text { weight of dose }}{\text { weight of standard }} \times \text { activity of standard. }
$$

The half-time of the linear part of the curve was measured and the slope constant $(\lambda)$ obtained from:

$$
\lambda=\frac{\log _{e} 2}{T_{t}}
$$

The plasma clearance is then given by $V \lambda$.

In each subject we measured Hypaque clearance before and after a single dose of aspirin. For the aspirin experiments we gave $20 \mathrm{mg} / \mathrm{kg}$ body weight (3-6 tablets of soluble aspirin) at the same time as the injection of Hypaque, and the two determinations on each patient were done on consecutive days.

\section{Results}

In 2 of the 15 patients the results did not fall on a straight line and could therefore not be used for measuring clearance. 


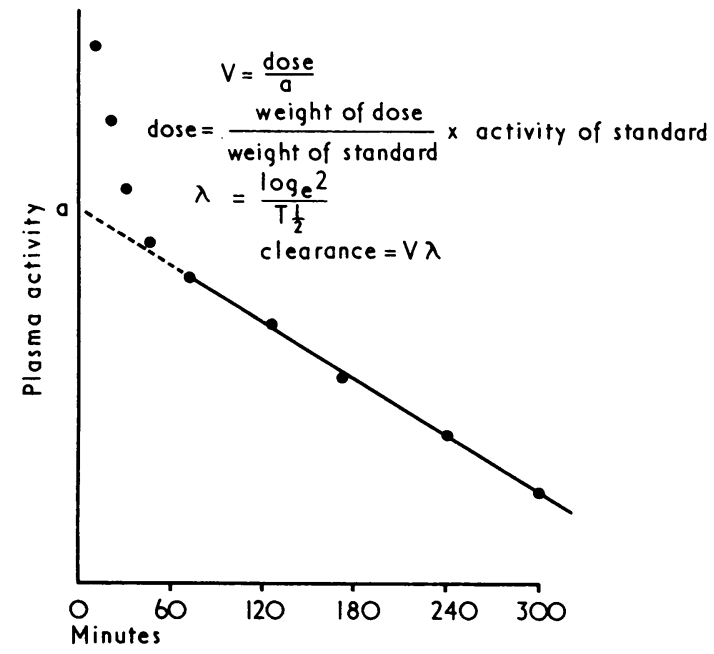

Plasma disappearance of Hypaque on a semilogarithmic scale.

Effect of Aspirin on Glomerular Filtration Rate

\begin{tabular}{|c|c|c|c|c|}
\hline \multirow{2}{*}{ Case No. } & & \multicolumn{2}{|c|}{ G.F.R. (ml/min) } & \multirow{2}{*}{$\%$ Change in G.F.R. } \\
\hline & & Before Aspirin & After Aspirin & \\
\hline $\begin{array}{r}1 \\
2 \\
3 \\
4 \\
5 \\
6 \\
7 \\
8 \\
9 \\
10 \\
11 \\
12 \\
13\end{array}$ & $\begin{array}{l}\ldots \\
\cdots \\
\cdots \\
\cdots \\
\cdots \\
\cdots \\
\cdots \\
\cdots \\
\cdots \\
\cdots \\
\cdots\end{array}$ & $\begin{array}{r}168 \\
87 \\
100 \\
90 \\
96 \\
151 \\
84 \\
124 \\
98 \\
126 \\
146 \\
163 \\
148\end{array}$ & $\begin{array}{r}139 \\
77 \\
88 \\
78 \\
78 \\
132 \\
69 \\
102 \\
96 \\
129 \\
131 \\
153 \\
148 \\
\end{array}$ & $\begin{array}{c}-17.3 \\
-11.5 \\
-12 \\
-13.3 \\
-18.8 \\
-11.3 \\
-17.8 \\
-17.8 \\
-2.0 \\
+2.4 \\
10.3 \\
-6 \\
0\end{array}$ \\
\hline & & & Mean & -10.5 \\
\hline
\end{tabular}

The results for the remaining 13 patients are shown in the Table.

Plasma salicylate levels were measured at three hours in 10 of the 13 patients and they ranged from 5 to $19 \mathrm{mg} / 100$ $\mathrm{ml}$, with a mean of $12 \mathrm{mg}$. There was no correlation between percentage change in clearance and the plasma salicylate level.

\section{Discussion}

Aspirin produces a significant reduction in glomerular filtration rate as measured by this method. Though there are many theoretical objections to a single-injection technique (Smith, 1951) it has been shown to correlate well with standard clearance procedures. Under normal conditions Hypaque is excreted rapidly and completely by the kidney, is not taken up by other organs, and is not significantly protein bound. There is good evidence that Hypaque clearance bears a constant relation to inulin clearance (Denneberg, 1965; Donaldson, 1968). Furthermore, in preliminary studies we found that Hypaque clearance by a single injection technique gave highly reproducible results, consecutive measurements of filtration rate varying by less than $5 \%$. We believe that it is accurate and reproducible enough to detect acute changes in filtration rate and that it therefore lends itself to studies of this kind.

The way in which aspirin produces its effect on the plasma clearance of Hypaque is unknown, nevertheless our results have important implications. In a techniaue which is becoming increasingly popular for following changes in glomerular filtration rate it is obviously vital to know that this measurement can be altered by a single therapeutic dose of a drug as common as aspirin. It would be of interest to know if other commonly used drugs had similar actions. The possibility that aspirin may acutely affect renal function is also of interest in view of its possible role in the long-term nephrotoxicity of analgesic substances.

We thank Dr. J. D. Blainey for helpful criticism and encouragement.

\section{References}

Chantler, C., Garnett, E. S., Parsons, V., and Veall, N. (1969). Clinical Science, 37, 169.

Denneberg, T. (1965). Acta Medica Scandinavica, 179, Suppl. No. 442

Donaldson, I. M. L. (1968). Clinical Science, 35, 513

Nanra, R. S., and Kincaid-Smith, P. (1970). British Medical fournal, 3, 559.

Smith, H. W. (1951). The Kidney. New York, Oxford University Press.

\section{Gall Stones after Peptic Ulcer Surgery}

\section{E. S. FIELD}

British Medical fournal, 1971, 1, 708-709

The case of a man developing gall stones after two peptic ulcer operations and a review of 406 other cases of gallstones are presented.

\section{St. James' Hospital, London S.W.12}

E. S. FIELD, F.R.C.S., Surgical Registrar (Present position: Research Assistant (Honorary Senior Registrar), King's College Hospital Medical School, London S.E.5)

\section{Case Report}

In 1961 a 60 -year-old man presented with indigestion for 30 years; barium-meal examination showed duodenal ulceration. At operation anterior and posterior ulcers were found and a Polya-type gastrectomy was performed. The gall bladder was normal. In 1966 further digestive symptoms were investigated and a stomal ulcer was found. Cholecystography showed nothing abnormal. At operation the normal gall bladder was confirmed and truncal vagotomy was performed for the ulcer. In 1967 still further indigestion occurred, and in 1968, after a cholecystogram showed a non-functioning gall bladder, cholecystectomy was performed for gall stones.

\section{Review of Previous Cases}

Altogether 406 patients found to have gall stones in the twoyear period from 1 January 1965 to 31 December 1966 were reviewed. Of these 26 had undergone previous ulcer surgery, when the gall bladder had been noted to be normal. (Table I). The predominance of the Billroth I procedure among the 